\author{
Proceedings of the $10^{\text {th }}$ International Conference on Applied Informatics \\ Eger, Hungary, January 30-February 1, 2017. pp. 309-315 \\ doi: 10.14794/ICAI.10.2017.309
}

\title{
Design thinking and digital innovation cooperative project*
}

\author{
Rastislav Žitný, Tibor Szabó, Štefan Balla \\ Constantine the Philosopher University in Nitra \\ \{rzitny, tszabo, sballa\}@ukf .sk
}

\begin{abstract}
Advanced technologies based on design thinking approach of process engineering are applied in process management of business and enterprises. Good practice example in management and applying design thinking approach in practice can contribute education at universities that enable better acquiring abilities to solve issues such way. Recent design thinking approach can inspire education processes including effect of improving the level of education. The combination of design thinking approach and modern technologies still intensifies the solution of educational issues. Wide spread of smart devices from personal computers and notebooks, across mobile communication to smart phones, tablets or signal devices and smart appliances enable to share signals, instructions, opinions, issues and experiences in design thinking approach and to innovate through digital innovation of the content of education. The paper presents current state of the Erasmus + project 2016-1-BG01-KA203-023719.

Keywords: Design thinking, digital innovation, business management, marketing, project management.
\end{abstract}

$M S C: 68 \mathrm{U} 20$

\section{Introduction}

At the beginning of the 21th century the design firm IDEO brought the concept of Design thinking. They overtook thinking of engineers, architects and designers to improve final view on the product, service from point of innovation in business focussing on works with clients with hands-on approach (see $[2,5])$ and management scholars who had collaborated with or observed the work of designers (see [1]). Design thinking is defined as "a discipline that uses the designer's sensibility and methods to match people's needs with what is technologically feasible and what a viable business strategy can convert into customer value and market opportunity"

\footnotetext{
${ }^{*}$ The paper presents current state of the Erasmus + project 2016-1-BG01-KA203-023719.
} 
(see [3]), and it is characterized by: 1) a cognitive style of individual designers involved in problem solving, 2) a general theory of design as a field or discipline focused on solving wicked problems, 3) an organizational resource for businesses and other organizations (see [5]). Design thinking has been described within a threedimensional framework of practices (ways of working), thinking styles (cognitive styles and ways of processing information), and mentalities (the mental attitudes of individuals and the organizational culture) (see [4]).

Several Design thinking models was published in the last decade, some of them are the 3 I model from IDEO (Brown \& Wyatt, 2010), which defines the design thinking process as a system of three overlapping spaces: inspiration, ideation and implementation; the HCD model, created as a toolkit for NGOs and social enterprises that work with impoverished communities in the developing world (http:// www.ideo.com/work/human-centered-design-toolkit), also developed by the design agency IDEO; the Design thinking model of the Hasso-Plattner- Institute (http://www.hpi.uni-potsdam.de/d_school/designthinking), developed in an educational context; the Double Diamond model from the British Design Council (http://www.designcouncil.org.uk), which describes the divergent and convergent stages of the design process, and the Service Design model proposed by Stickdorn and Schneider (2010), which describes the Design thinking process as an iterative process composed of the phases of exploration, creation, reflection and implementation.

Engineers think about machinery at the design phase from various points of view. First, it is functionality and purpose, next, construction and production matters. Then it is whole works and producing technology, structural sizing of forces and stress. Preparing complex design of machinery requires using appropriate materials, ergonomic solutions and industrial design with colour and shape. Nonetheless, in building architecture we consider about historic era, its composition, incorporation in site, in social environment. We can explore purpose of the buildings and their utilization. Over and above we consider about technical solution, structural elements etc. Finally, we evaluate the way that designers rise to the occasion.

thinking processes from study of engineering disciplines introduced above can be overtaken and applied in education. Point is that, how to apply processes and methodology teach engineering thinking. And more, such processes can apply in social sciences and art. Basic attributes of such process are inspiration, discovery, ideate (fig. 1), interpretation, prototyping, realisation, testing etc. They have common denominators what is innovation and improvement.

\section{Main objectives}

Design thinking is methodology of implementation of innovation not only in university education. There are several methods of Design thinking according to inventors or providers on their approaches. Design thinking offers application of wide range of disciplines focused on solving various problems. It enables problem solving experiences through discovery of problem, definition of problem, ideation or finding 


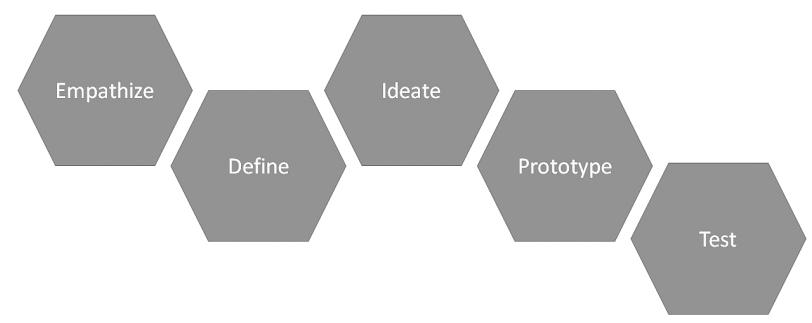

Figure 1: Design thinking process according to Stanford

valid question with prototyping or practising and testing of arising solution.

Main objectives are enable students through the motivating teaching and learning strategies and focused on problem solving with acquiring core skills valuable for employers. The aim is to prepare problems and scenarios for lectures, workshops and assignments based on Design thinking methodology and teach students to adopt and use them in solving real assignments in university field and real life as well.

Our approach in motivating teaching and learning strategies is supported by opinions of students and by faculty view. European Reference Framework sets eight key competences. We go further in considering skills with notion of employers and faculty. Employers suggest their view what presents crucial needs of skills and faculties amend to complete wide scale of important skills.

From students applying of Design thinking we expect procedures linked to original concepts with ideas and solutions in new innovative solutions elaborated in prototyping and testing them in practical experience. They anticipate in collaborative activities and communications with other students. Students incorporate elements of creative industry and design.

\section{Scope and methods}

Due to acknowledgement of Erasmus + program, the Design thinking and Digital Innovation project can develop learning and teaching strategies and students' skills and adapt study courses of high education institutions according to requirements of employers. Project focuses on methodology and content based learning within the on-line courses which include tools, templates, concepts, etc. Originally, we intent to apply Design thinking methodology in subjects; business management, project management and marketing.

We are doing our research in the field of engineering and business disciplines, where faculties are specifying on ICT, business administration, innovation and education. Our interest concerns on three different areas, generally they are competences, skills and teaching and learning strategies. First, we ask for instrumental generic competencies, systemic generic competencies, and interpersonal generic competencies. Secondly, it seems to be important skills for digital in- 
novation. Thirdly, there are teaching-learning strategies focused on activity-based strategies, arts-based strategies, cooperative strategies, direct-instruction strategies, ICT-based strategies, independent learning strategies and inquiry-based strategies. Students engaged to project are studying in bachelor and master degree programs. Innovation in teaching and learning process requires collaboration with business sector. It represents most relevant ideas and necessities to teach and learn competencies and skills. Variety of methods and approaches from creative industries can find solutions to solve problems by Design thinking keeping business purposes in mind.

Main skills and strategies come from questionnaire research. We got answers from 111 respondents in questionnaire. They represent university students, faculty teachers and employers. Results were shown according to tracking mean value of Likert scale, where the responses were particular values: relevant, very important, or critical value for competences; not important, important, very important or critical value for skills, and not effective, effective or very effective value for strategies. Respondents explained on their own what they consider to teach for best assert in business. We refer only relevant results which are statistically significant. Table 1 shows most valued skills from point of view of employers and faculty. Table 2 shows most valued motivating teaching-learning strategies from point of view of students and faculty.

\begin{tabular}{|c|c|}
\hline Students & Faculty \\
\hline Oral presentations & \\
\hline & Debate and discussions \\
\hline Simulations & Simulations \\
\hline $\begin{array}{c}\text { Games } \\
\text { Role-play }\end{array}$ & Role-play \\
\hline Conflict resolution & Conflict resolution \\
\hline Mentoring & Peer teaching \\
\hline Peer teaching & Guest speaker \\
\hline Guest speaker & Storyboard \\
\hline Brainstorming & Homework \\
\hline & Lateral thinking \\
\hline Experimentation & \\
\hline
\end{tabular}

Table 1: Most valued skills for Digital Innovation

\section{Design thinking course}

Construction of course on Design thinking is designed on found skills and competences. Within the course teachers of high school institutions and universities will be trained on Design thinking methods to be able to apply such methods in their 


\begin{tabular}{|c|c|}
\hline Employers & Students \\
\hline Creative thinking & Creative thinking \\
\hline & Critical thinking \\
\hline Digital competences & \\
\hline Problem solving & Problem solving \\
\hline Team thinking & \\
\hline Creativity & Creativity \\
\hline Customer orientation & Customer orientation \\
\hline Flexibility & \\
\hline Initiative / Proactivity & Initiative / Proactivity \\
\hline Innovation & Innovation \\
\hline & Adaptability \\
\hline Teamwork & Teamwork \\
\hline
\end{tabular}

Table 2: Motivating Teaching-Learning Strategies for Digital Innovation

lessons. There are practiced workshops, analysis, scanning, and interactions with customers, empathic maps and process analysis. First, they will define problem to solve, real frame of the problem and why it has to be solved. How are common problems solved? Second, teachers will define of scope and expect value for problem to be solved. Third, after generating of inventions and building the solution they add or remove operation, determine values to do, eliminate of negative effects and set innovative principles. Fourth, teachers will prototype from paper, model, testing video or programmed menu, vital product or service, which can be tested to acquire feedback. Fifth, they will test solution deployment and evaluate, explore of responds, set new inspirations, correct and improve solution, provide feedback, discussions, learning and teaching. And last, sixth, they will apply and conclude principals and methods of Design thinking. After they will include principals of Design thinking in subjects.

\section{Learning outcomes according to authors of the project}

We present learning outcomes as they are planned according to authors of the Erasmus + project for the participants to be able to:

- Have an awareness of the role of Design thinking in Innovation and how it can be applied in a wide range of contexts.

- Adopt innovation attitude to turn ideas into solutions that add value to a product, process, or service applying Design thinking model.

- Apply design thinking frameworks to articulate a project question aimed 
at addressing a problem or creating and pursuing an innovative idea from imagination to prototyping/creation.

- Use creative techniques in generating novel and useful ideas and defining and prototyping products, services and business models that allow visualizing possible solutions.

- Develop empathy with peers and clients and apply human-centered methods to research and build towards a solution for a problem or new service.

- Use divergent and convergent thinking, synthesize unconventional ideas and points of view to uncover new solutions.

- Collaborate within a multidisciplinary context and leverage the diversity of perspectives and differences to build robust solutions.

- Use sketching as well as various prototyping techniques for products and services.

- Communicate effectively in oral and written format the output of their thinking and generate interest and support for the adoption or implementation of the idea.

- Evaluate the potential of a design or solution through analytical and synthetic thinking approaches.

- Use computing tools and online environments to aid design thinking.

\section{Applying Design thinking process}

Originally during applying Design thinking methods we set the main problem to be solve. Process of design thinking consists from several phases. We are applying Onset problem information are reached through available sources, mainly internet, from familiar persons or other way. Other way of participating on the problem is using opportunities to meet real situations, communicate through e-mail or use information from business environment.

During the first phase, so called the discovery phase, we think about general specifications, ask questions, what are the factors, which motivates solving problem, what expectations brings solution of the problem. These questions try to uncover range of conditions, acquire answers from client, let him to explain all requirements and know genuine opinion of real people. In second phase called the define phase, there are time to suggest questions on controlled interview and find preferences, how to be successful in solving the problem. Within this phase we acquire set of topics or themes that to be applied in next phase for example how to scheduling, questions on trust, quality or time stress. Third phase is called ideate phase so called IOX phase. Here we set number of questions. The aim is to require 
emotions and share thoughts. IOX means ten questions or "tenexing". Ten questions promotes quantity of ideas to produce one question presenting quality, by other words any ten questions will produce one principal question. More questions means more opportunities whereby we prefer quantity over quality with maximal effort to acquire emotional impact. Fourth phase is practical phase when we create prototype of the problem from paper or by sketching, or create programmed menu, product or service, etc. In last phase prototype is tested.

According to process above participants of the Erasmus + project yield scenarios for most valued skills and for motivating teaching-learning strategies for Digital Innovation as a main task of the project. Prepared scenarios take regard on Bloom taxonomy of learning objectives.

\section{Conclusion}

We are preparing the international meeting with syllabi based on Design thinking to practise techniques of scenarios. There we will lead workshop and discussions on up to date questions on Design thinking. Variety of participants will take place at the workshop, teachers of high educational institutions and universities, and deputies of retraining educational institution, students and project solvers. Present challenge focuses on preparing valuable scenarios based on the results of research and to be able to apply such methods in lessons. Scenarios will apply methods and strategies of engineers, designers or architects together with various schemas, graphic organizers, Venn diagrams, mind maps, affinity maps etc.

Design thinking features the importance of designing of problems for constructing of individual approach by generating wide range of ideas before final decision, testing, preparing prototypes with real visions before adopting final solution.

\section{References}

[1] Boland, R. J., Collopy, F., Managing as Designing. Stanford Business Books, Stanford University Press, (2004).

[2] Brown, T., Change by Design: How design thinking transforms organizations and inspires innovation, NY: HarperCollins, (2009).

[3] Brown, T., Design thinking, Harvard business review, (2008), 84-92, 141.

[4] Hassi, L., LaAkso, M., Design thinking in the management discourse: defining the elements of the concept. (2011).

[5] Kimbell, L., Rethinking design thinking: Part I. Design and Culture. The Journal of the Design Studies Forum. Vol 23, (2011).

[6] Virtual Crash Course Video, (2017), online: https://dschool.stanford.edu/ resources/virtual-crash-course-video.

[7] A Model of Learning Objectives, (2017), online: http://www.celt.iastate.edu/ teaching/effective-teaching-practices/revised-blooms-taxonomy. 